\title{
Addendum
}

\section{The entD gene of the Escherichia coli K12 enterobactin gene cluster}

\author{
Peter E. Coderre and Charles F. Earhart
}

Journal of General Microbiology (1989), 135, 3043-3055.

The authors wish to add the following statement:

In this paper we neglected to cite an abstract (Armstrong et al., 1989a) in which sequencing of the entD gene and localization of its product was reported. Also, since our paper appeared we have become aware of a paper (Armstrong et $a l ., 1989 b$ ) detailing the results presented in the above abstract. We also wish to (i) cite our abstract (Coderre \& Earhart, 1986) in which the plasmid (pPC5-4) containing an ent $D:: \operatorname{Tn} 5$ mutation was first described, and (ii) acknowledge that the studies we reported were primarily taken from a dissertation submitted by Peter E. Coderre to the Graduate School, The University of Texas at Austin, in partial fulfilment of the requirements for the PhD degree.

\section{References}

Armstrong, S. K., Pettis, G. S., Forrester, L. J. \& McIntosh, M. A. (1989a). Nucleotide sequence of the Escherichia coli enterobactin biosynthesis gene entD and localization of its protein product. In Abstracts of the Annual Meeting of the American Society for Microbiology 1989, K157, p. 271.

Armstrong, S. K., PetTiS, G. S.; Forrester, L. J. \& McINTOSH, M. A. (1989b). The Escherichia coli enterobactin biosynthesis gene, ent D: nucleotide sequence and membrane localization of its protein product. Molecular Microbiology 3, 757-766.

Coderre, P. E. \& EARHART, C. F. (1986). Characterization of a plasmid carrying the Escherichia coli K-12 entD, fepA, fes and entF genes by Tn5 mutagenesis. In Abstracts of the Annual Meeting of the American Society for Microbiology 1986, H177, p. 157. 